International Journal of Trend in Scientific Research and Development (IJTSRD)

Volume: 3 | Issue: 3 | Mar-Apr 2019 Available Online: www.ijtsrd.com e-ISSN: 2456 - 6470

\title{
Multiple Products Testing on Single Circular Conveyor
}

\author{
Neeraj Kumar Sharma1, Apoorv Sharma², Aayushi Pandey ${ }^{2}$, Chandrakant Jaiswal'2, Akarsh Gupta² \\ ${ }^{1}$ Sr. Assistant Professor, ${ }^{2}$ B.Tech Student \\ 1,2Department of Mechanical Engineering, ABES Engineering College, Ghaziabad, Uttar Pradesh, India
}

How to cite this paper: Neeraj Kumar Sharma | Apoorv Sharma | Aayushi Pandey | Chandrakant Jaiswal | Akarsh Gupta "Multiple Products Testing on Single Circular Conveyor" Published in International Journal of Trend in Scientific Research and Development (ijtsrd), ISSN: 24566470, Volume-3 | Issue-3, April 2019, pp.1096-1099, URL: https://www.ijtsrd.c om/papers/ijtsrd23 240.pdf

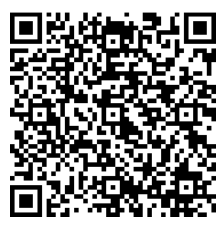

IITSRD23240

Copyright (C) 2019 by author(s) and International Journal of Trend in Scientific Research and Development Journal. This is an Open Access article distributed under the terms of the Creative Commons Attribution License (CC BY 4.0) (http://creativecommons.org/licenses/ by/4.0)

\section{INTRODUCTION}

This is an era of automation where it is broadly defined as replacement of manual effort by mechanical power in all degree of automation. The operation remains an essential part of the system although with changing demands on physical input as the degree of mechanization is increased. This system begins with an introduction to product inspection on various parameters such as dimension, colour, metal or non-metal and moisture using various sensors which are mounted on the periphery of a circular conveyor which is driven by an electric motor.

The manual intervention can be reduced drastically by using this modern setup. It also reduces inspection time, space required for testing and cost.

This paper initially presents an overview of the main concepts related to detection and treatment of faults in manufacturing systems. In Section 3, a methodology that describes the working of the system is introduced. In Section 4 , flow chart is presented. In section 5 , various components used in the system are discussed. Finally, in Section 6, Results and discussion are presented.

\section{LITERATURE REVIEW}

Despite advances in automation technology, faults are events that cannot be ignored in a real manufacturing system. However, most reports in technical publications consider only the description and optimization of processes under normal conditions (Zhou and DiCesare, 1993). Thus, the development of a methodology that considers not only normal processes but also the multiple testing of products is essential for improving the flexibility and autonomy in manufacturing systems.

Multiple product testing finds application in large number of industries. The most important application of the system is in segregation of Industrial by products.

Dutch industry generated 20.2 million tons of industrial waste in 2016, 3 percent less than in 2015. Eighty-three percent of this waste is recycled; the remainder ends up on dumping sites (7 percent) and in waste incineration plants (8 percent).

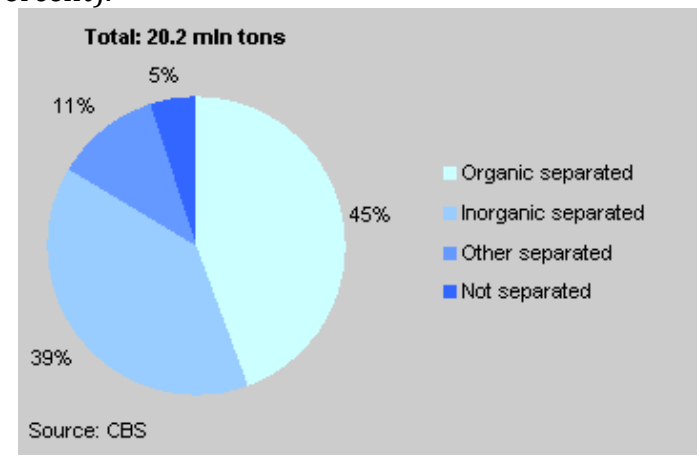

Fig. 1: Industrial Wastes 2016 


\section{WORKING METHODOLOGY}

There is a circular conveyor where the object is put down from the first conveyor.Different sensors and servo motors are mounted on the periphery of the circular conveyor (conveyor 2) which do the inspection of the object and Servo motors are used to sort the defective products. The quality passed object are passed on the third conveyor using sorting arm from the circular conveyor which finally reaches the initial position.

The 12 volt power supply is used to drive the permanent magnet D.C motor. The two conveyor roller is fixed to the two ends of frame stand. On the first conveyor a metal sensor along with an IR sensor is mounted.

Metal sensor is used to detect whether the object is metal or non-metal. IR sensor is used to check the presence of any object using photo diode.

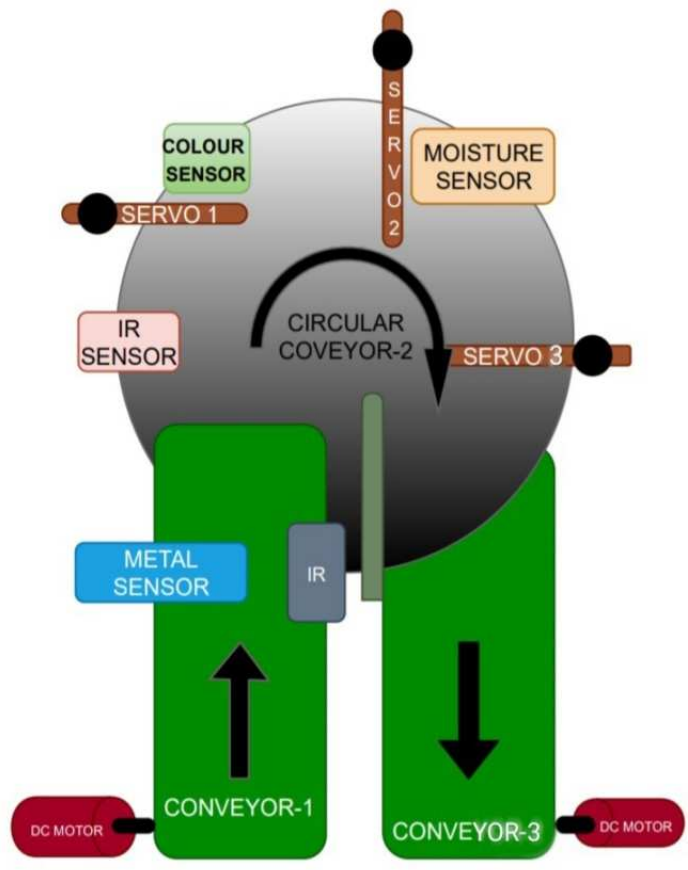

Fig. 2: Working Model

The system is designed for two set of combinations 1. Metallic Products- Testing of dimension and colour 2. Non Metallic Products- Testing of colour and moisture

CASE 1: If the product is metallic then metal sensor would actuate the IR sensor and colour sensor (mounted on the circular conveyor)

If the length of the product is acceptable then it would pass through the IR sensor otherwise it would be sorted and displaced from the circular conveyor with the help of servo motor placed just after the IR sensor.

The length accepted product is then passed through the colour sensor. If the colour of the product is acceptable then it would pass to the third conveyor otherwise it would be sorted and displaced from the circular conveyor with the help of servo motor placed just after the colour sensor.

CASE 2: If the product is non- metallic then metal sensor would actuate the colour and moisture sensor (mounted on the circular conveyor)
If the colour of the product is acceptable then it would pass through the colour sensor otherwise it would be sorted and displaced from the circular conveyor with the help of servo motor placed just after the colour sensor.

The colour accepted product is then passed through the moisture sensor. If the product is moisture free then it would pass to the third conveyor otherwise it would be sorted and displaced from the circular conveyor with the help of servo motor placed just after the moisture sensor

IV.

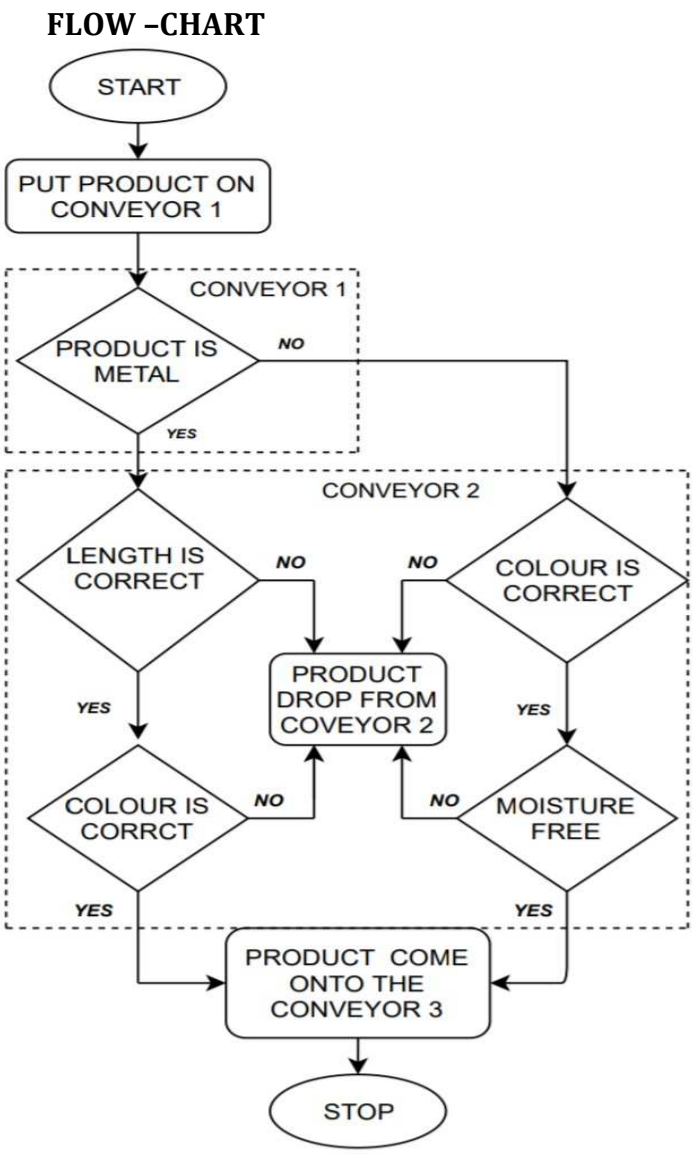

Fig. 3: Flow Chart

\section{COMPONENTS USED IN THE SETUP}

All the components are discussed below in details.

A. Conveyor

A belt conveyor consists of an endless belt of a resilient material connected between two pulleys through a drive unit gearbox, which is connected to an electric motor. Product is conveyed by placing it on the belt, through a feeder. As the belt rotates, the product is carried with it on the other end, where it is then dropped in the dropped in the discharge chute. Roller wheel help to rotates conveyor system. In our system the conveyor is the main medium to carry products for the multiple testing. The product to be tested is placed on the conveyor belt. This system uses 3 conveyor belts ( 2 straight conveyors and 1 circular conveyor)

The system is designed in such a way that the final position of the accepted product is same as the initial position.

MAJOR EQUOMENTS OF BELT CONVEYOR SYSTEM
A. Conveyor belt and Conveyor disc
B. Rollers and Idlers
C. Bearing and Motor
D. Structural Frame 


\section{B. Sensors}

There are various types of sensors used in the system.

1. Metal Sensor

Metal sensor is mounted on the first conveyor. It is used to check whether the product is metallic or non metallic.

Specifications:

No. of wires- 3

Detection distance- $4 \mathrm{~m}$

Operating voltage- $12 \mathrm{~V}$

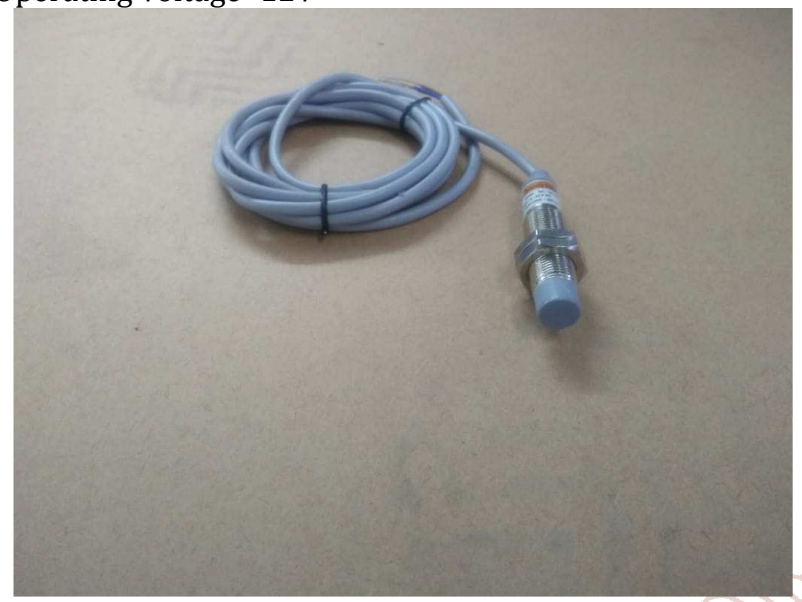

\section{IR Sensor}

Fig. 4: Metal Sensor

IR sensor is used to check the presence of any object. It consist of transmitter and receiver which forms a photo diode.

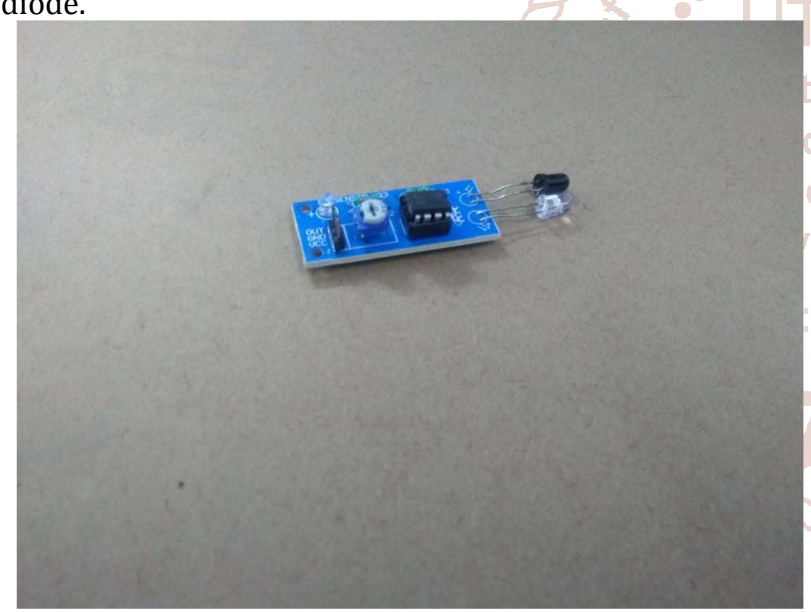

Fig. 5: IR Sensor

\section{Colour Sensor}

Colour sensor is used to determine the colour of object. It emits different frequencies of different colour. The reading comes out in the form of analog value which is equivalent to a particular colour.

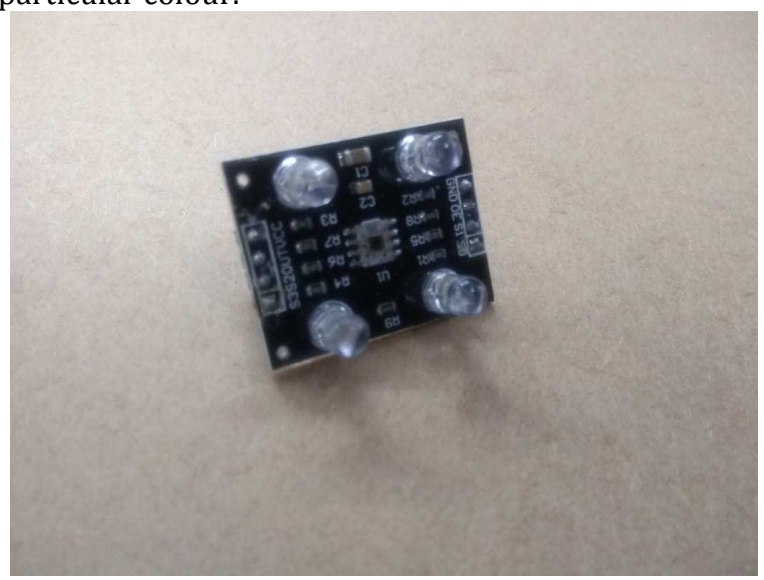

Fig. 6: Colour Sensor
4. Moisture Sensor

Moisture sensor is used to detect the presence of any moisture on the product. It is used to check the connectivity of the object. It consist of a conducting plate and when the moisture is detected voltage change take place. An amplifier is provided which amplifies the resistance change.

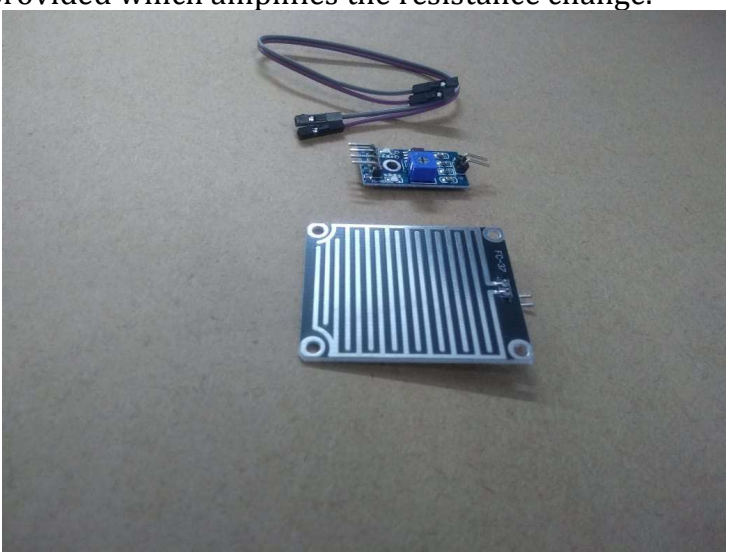

Fig. 7: Moisture Sensor

\section{Arduino Nano}

Arduino Nano is a small, compatible, flexible and breadboard friendly Microcontroller board.It comes with an operating voltage of $5 \mathrm{~V}$, however, the input voltage can vary from 7 to $12 \mathrm{~V}$.

Arduino Nano Pinout contains 14 digital pins, 8 analog Pins, 2 Reset Pins \& 6 Power Pins.

Each of these Digital \& Analog Pins are assigned with multiple functions but their main function is to be configured as input or output.

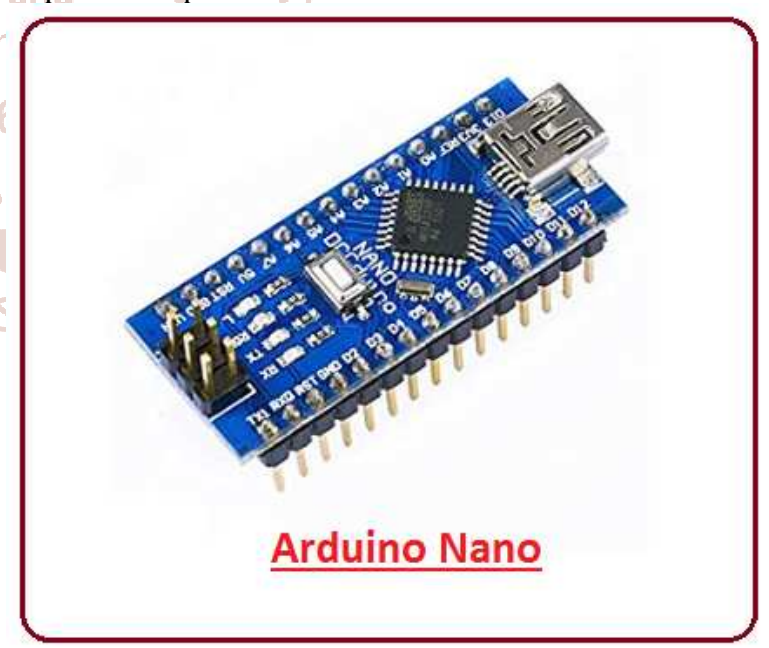

Fig. 8: Arduino Nano

\section{Servo Motor}

The Servo Motor basically consists of a DC Motor, a Gear system, a position sensor and a control circuit. The Gear and shaft assembly connected to the DC motors lower this speed into sufficient speed and higher torque. The position sensor senses the position of the shaft from its definite position and feeds the information to the control circuit. The control circuit accordingly decodes the signals from the position sensor and compares the actual position of the motors with the desired position and accordingly controls the direction of rotation of the DC motor to get the required position. The Servo Motor generally requires DC supply of $4.8 \mathrm{~V}$ to $6 \mathrm{~V}$. 


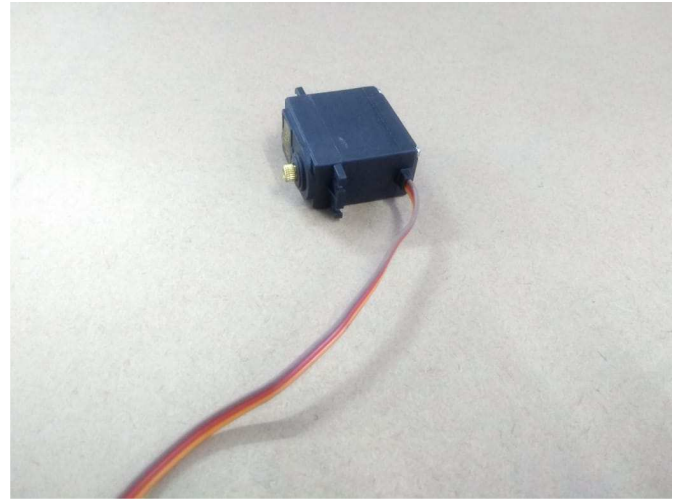

Fig: 9 Servo Motor

\section{RESULT AND DISCUSSION}

The output of the system is that multiple products are tested and segregated on the basis of various attributes. The acceptable product can now be further used in the industry and the segregated products can be recycled or can be considered as waste.

\section{CONCLUSION}

This system eradicate the problem of different setups and space requirement for multiple product testing and helps in reducing cost.

\section{REFERENCES}

[1] B. K. Bhattacharya, S. Das, "A holistic approach for integrated solid waste management system of Kolkata municipality corporation area," IEEE Conference, vol. 3 , no.8,pp.1999-2003,2011
[2] J. Choi, T. Hayashi, S. Endoh, H. Sakamoto, "Separation of metallic particles by vertical vibration for solid waste treatment," IEEE Conferences, pp. 936-941,1999

[3] T. Hartikainen, J. P. Nikkanen, R. Mikkonen, "Magnetic separation of industrial waste waters as an environmental application of superconductivity," IEEE Journals \& Magazines, vol. 15 , pp. 2336 - 2339, 2005.

[4] J. Boulton, "Waste management and its role in the Canadian fuel cycle," IEEE Journals \& Magazines, vol. 4, pp.31-34,1979.

[5] Rahul: H. Lauhoff, Germany (2005) "Speed Control on Belt Conveyors -Does it really Save Energy?"

[6] Rahul: Handbook of conveying and handling of particulate

[7] solids-Avi levy,Haimkalman, Volume 10 of Handbook powder technology, ISSN 0167-3785(2001)

[8] S. S. Vanamane,P.A.Mane, K. H. Inamdar(2011) “Design and its Verification of Belt Conveyor System used for Cooling of Mould using Belt Comp Software'

[9] radosław zimroz, robert król (2009)“Failure analysis of belt conveyor systems for condition monitoring purposes"

[10] A.W. Roberts (1981) "Economic analysis in the optimization of belt conveyor systems"

[11] Raghvendra Singh gurjar, Arvind yadav, Pratesh jayaswal (May 2012) "Failure analysis of belt conveyor system in a thermal power plant"

[12] Larry Goldbeck (9th International Conference-2007) "Improving Belt Conveyor Safety With Better Procedures and Training"

[13] H. Lauhoff, Germany (2005) "Speed Control on Belt Conveyors -Does it really Save Energy?" 